\title{
Examining the dynamics of decision making when designing curriculum in partnership with students: How should we proceed?
}

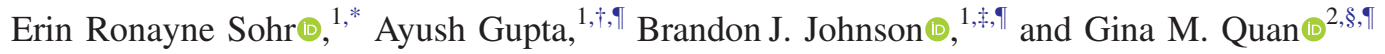 \\ ${ }^{1}$ Department of Physics, University of Maryland, College Park, Maryland 20742, USA \\ ${ }^{2}$ Department of Physics \& Astronomy, San Jose State University, San Jose, California 95112, USA
}

(Received 8 July 2019; accepted 23 March 2020; published 4 December 2020)

\begin{abstract}
[This paper is part of the Focused Collection on Curriculum Development: Theory into Design.] Common models of curricular development in physics education research (PER) have typically involved a hierarchical relationship between researchers and students, where researchers lead the design and testing of curriculum for students. We draw from work in students as partners and related fields in order to codesign curriculum in partnership with students. Such work has the potential to disrupt typical hierarchical relationships and interactions between students and faculty by involving students in the process of making curricular decisions. We invited undergraduate students to participate in a partnership to codesign a set of curricular materials for topics in quantum mechanics that students often struggle with. Four undergraduate students, one PER graduate student, and one PER faculty member met for a series of codesign meetings. We collected videotapes of the meetings, written artifacts, and meeting reflections. This paper presents a fine-grained analysis of one interaction in which researchers attempted to create space for students to contribute to decision making about how the collaboration should proceed. Through analyzing the complex dynamics of how participants negotiated decision-making space, including characterizing the types of decisions that were made, we describe how access to those decisions were opened up or cut off, and how those decisions contested or reaffirmed participants' roles. Working towards partnership is a complex and messy process: attempts to open up space for some forms of decision making closed off access to other forms of decision making. In some ways, the interactions between the participants also reified the traditional student and faculty roles that the partnership had intended to disrupt. Through closely analyzing these dynamics, we aim to self-critically reflect on the challenges and tensions that emerge in codesign partnerships. We discuss our own areas for growth and speak to implications for more responsible partnerships.
\end{abstract}

DOI: 10.1103/PhysRevPhysEducRes.16.020157

\section{INTRODUCTION}

While the development of curricular materials has been a central component of physics education research (PER), the involvement of students in the curricular design process has been limited. PER researchers have collected student data in order to align curriculum with common student difficulties and beliefs, assess the effectiveness of curricula, and inform revisions to curricula [1-4]. These forms of data have also been typically limited to students' conceptual

\footnotetext{
*esohr@umd.edu, she/her/hers

ayush@umd.edu, they/them/theirs or he/him/his

brandon.johnson110@gmail.com, he/him/his

\$gina.quan@sjsu.edu, she/her/hers

"Authors contributed equally to this work.
}

Published by the American Physical Society under the terms of the Creative Commons Attribution 4.0 International license. Further distribution of this work must maintain attribution to the author(s) and the published article's title, journal citation, and DOI. knowledge and epistemologies. This involvement of student data suggests that students' experiences and knowledge are informative in the process of curricular design. This work has valued student perspectives for the purposes of informing how faculty and/or researchers design curricula for students.

An alternative curricular design model involves designing curriculum in partnership with students. This process, called students as partners (SAP), has been gaining traction in broader education research and scholarship of teaching and learning communities, e.g., see Refs. [5,6]. SAP involves a shift in, and empirical focus upon, the process of curriculum design; rather than having researchers and instructors as the "deciders" in curricular issues, students and faculty engage in decision making together. This deviates from typical student-faculty relationships in higher education [5]. Literature suggests that SAP work results in positive outcomes-curricula that are better tailored towards their target populations, improved learning outcomes for students, and positive affective and attitudinal benefits for students and faculty [6,7]. At the same time, 
literature and our own experiences suggest that SAP also comes with a unique set of challenges. Negotiating these partnerships challenges typical relationships between students and faculty, and therefore involves navigating a complex web of expectations, emotions, and histories.

This study describes one effort to implement aspects of SAP ideology in the process of curricular design. We invited undergraduate students to participate in a series of meetings developing curricular materials on quantum mechanics. We analyze how participants (undergraduate students, graduate student, and faculty member) negotiated and renegotiated who contributes to decision making. We focus on one meeting in which facilitators made attempts to invite students into making decisions about how the group should proceed. Using fine-grained analysis, we show that attempts to make space for students to engage in that process led to a series of misunderstandings and confusion (interactional trouble) and attempts to repair the conversation. This cascade of trouble and repairs in some ways reified traditional student and faculty roles.

This self-critical piece aims to understand how we unintentionally reproduced some of the very power dynamics we had intended to disrupt. Through conducting these analyses, we identify areas for growth as we work towards more partnership-oriented work. We hope that this work will help other educators who are interested in partnership work be more aware of and able to notice moments in which hierarchies becomes unintentionally reproduced.

In the next section we discuss background literature on students as partners and the dynamics of roles and responsibilities in such partnerships. Then we describe the context of our study, the recruitment procedures for student partners, the data collection methods, and the orientation and methodological tools that informed our analysis. We next present a summary of our findings to help the reader form a broader frame that can help the comprehensibility of the following section that presents the details of our findings. Finally, we end with discussing how our work provides theoretical insights into shared epistemic agency and calls for more self-critical and non reductionist analysis and design of partnerships with students.

\section{BACKGROUND LITERATURE}

\section{A. Students as partners and related partnership work}

Students as partners is an idea that has been gaining traction in curricular design and institutional change. SAP refers to the involvement of students in educational decision making [7-9]. SAP (and related ideas) have been implemented across many contexts, including curricular design, course transformation, and department-level changes [7,10-12]. Many people have outlined the benefits of SAP-based curricular and departmental innovations. Because students better understand their own perspectives than faculty, these initiatives can better align with the populations they are trying to serve [13]. Research has documented how these partnerships can be mutually beneficial to both students and faculty involved; students report increased content learning, engagement, and selfefficacy, and faculty report improved curricular materials, better understanding of student experiences, and shifts in teaching practices [7]. This work suggests that SAP can affect many important dimensions of teaching and learning.

A key feature of SAP is shifting the processes by which decisions about education get made [5]. While traditionally educational decisions are made for students by faculty and staff, SAP involves faculty and staff making decisions with students. A framework by Bovill and Bulley articulates the spectrum of ways that students can be involved in decision making, ranging from limited influence (e.g., students give recommendations on a set of choices) to more influential forms (e.g., students and faculty negotiate the curriculum, or students are given control of a prescribed area) [11]. These partnerships are constantly evolving, and students' levels and domains of influence can shift over time.

Our conceptualization of SAP is informed by a larger landscape of work that involves partnership between researchers or designers and people who have not typically been involved in design work. For example, work in participatory design [14-16] involves doing design in partnership with users. Design-based research and participatory design research has involved the codesign of curricula and research between teachers and researchers [17-20]. A related and overlapping process called codesign involves designing curricula in partnership with teachers [21]. A key point of these areas of work is a rejection of typical relationships between researchers or designers and users. In a more traditional relationship, researchers or designers gather information about the users' experiences as inputs, but users themselves have little to no input in the decision making process. Codesign challenges that hierarchy by inviting users into the design process.

Some research about codesign has characterized forms of interaction between participants. Work by Sabella et al. (2016) describes how some student-faculty partnerships can involve faculty seeking input from student learning assistants but with faculty as the deciders (faculty driven partnerships), whereas other partnerships involve cogenerating content and activities (collaborative partnerships) [22]. A SAP framework from Bovill (2017) articulates the different stages in the design process that students can be involved in, for example, in the initial design of a course or intervention, in designing evaluation, in conducting evaluation, and disseminating results [23]. This framework also describes the different roles students can have with respect to decisions (informing, consulting, participating, partnership, control) [23,24]. Other research has analyzed how partnerships can have different divisions of labor (e.g., making all decisions collaboratively versus agreeing to delegate some responsibilities) [25]. The division of labor 
and level of decision making can shift over time. In summary, even within the language of "partnership" there seem to be differences in enactments, including how interactions are structured, what stage in the design process participants are involved in, and the aspects of the design in which different participants give input.

\section{B. Unpacking relationship negotiation in partnerships}

Some research notes the tensions and challenges that exist in SAP, e.g., Refs. [26,27]. These difficulties include resistance to sharing power (from all parties), struggles to achieve common ground, and tokenization of student voice $[7,10,28]$. Some work has discussed these difficulties in terms of cultural and institutional barriers: university cultural norms of who is typically involved in educational decision making, institutional features and structures (e.g., departmental rules about committee membership), and the long-standing hierarchies and power relationships in higher education [7,23]. Research on tensions in SAP has typically been reflective and/or ethnographic, which is helpful towards discussing these larger cultural structures, but makes it difficult to understand how these tensions emerge within interactions. In order to more deeply understand these tensions, it is important to look at how relationships between students and researchers get negotiated during interactions.

We draw on work which studies how relationships become negotiated, reproduced, and contested interactionally. Some research shows that people can often unintentionally reproduce existing hierarchies, even when they are explicitly trying to contest them [29,30]. For example, Carlone and Webb describe their attempts to design curricula in collaboration with teachers, and challenge typical didactic models of teacher professional development. Using fine-grained analysis of participants' speech, they analyzed how all participants sometimes reproduced and contested aspects of traditional professional development relationships [29]. Studying these processes of negotiation and renegotiation, they argue, allows them to identify moments where hierarchy could have been contested. Such analysis avoids individual-focused explanations that locate the responsibility within actors and purely institutional explanations, which can reify these cultural patterns and ignore actors' agency.

We share the orientation that this negotiation process is ongoing and messy; hierarchies can be reproduced and contested over time in complex ways [21,29,31]. We aim to understand these dynamics as they play out in decision-making processes in codesign. This interest in fine-grained dynamics leads us to use microgenetic methods. A microgenetic account is necessary because tensions and renegotiations of relationships are often visible in a moment-to-moment timescale [29,30].

Unpacking these challenges at the microgenetic timescale complements the coarse-grained descriptions of tensions and challenges in SAP work. Our methods allow us to ask in what ways are traditional university relationships reproduced, and in what ways are they contested. Moreover, we can understand the implications of these reproductions and contestations on the broader trajectory of the partnership. In understanding how these moments opened up or limited opportunities for partnership, we are able to self-critically reflect on how to better collaborate with students in curricular design.

\section{METHODOLOGY AND ANALYTICAL PROCESS}

\section{A. Context of the study}

This codesign project was developed in the context of an NSF-funded quantum mechanics (QM) undergraduate curriculum development project. As mentioned above, this study constitutes a snapshot of our stepping out and reflecting back on our processes as we move towards more participatory models of research and curriculum development.

The UMD Physics Education Group has a long history of developing tutorials aimed at various levels of undergraduate physics courses. The tutorial design process typically involved students in more distanced, but typical in PER, ways; through research on student thinking, having student(s) "test" tutorials, and editing and refining based on students' reasoning. These design processes were well entrenched in other group practices such as publishing on the products developed through these processes, applying for grant funding on these processes and papers published, and apprenticing new group members into these methods of curriculum design. This entrenchment also meant that the processes and forms of student involvement in curriculum design became taken for granted until a precipitating experience helped initiate movement towards different forms of student participation in curriculum design.

Several years ago, an education conference hosted a panel on QM-related research on teaching and learning. A student in attendance questioned the personal relevance of the undergraduate QM curriculum. The session ended on a heavy note-here was a student, a person for whom our work aimed to benefit, who felt deeply dissatisfied with their experience. In conversation with another researcher in attendance, Ayush was able to step back from the design practices that naturalized ideas of students' involvement as testers and end-users and reconstruct students as stakeholders who had been missing from the design process. These moments provided the motivation to learn more about participatory design methods and to try and initiate some of that in our local project contexts. It was through continued support of fellow researchers (especially Angela Little, Chandra Turpen, and Jennifer Radoff), consulting diverse bodies of literature using participatory methods, and consultation with a participatory action researcher, 
Tara Brown, that we have been able to take our first few steps towards participatory curriculum design.

Our first step involved creating more opportunities to learn about student experiences more broadly, beyond just how they think about quantum mechanics. With students, we made sense of their experiences in QM-but QM as situated within peoples' lives-in order to better understand the people we are designing for. We feel that "better" learning materials would be created by carefully designing for people, not just designing for QM sense makers.

Springboarding from these insights, our group took a first pass at developing a draft of a tutorial on quantum angular moment. Students were then recruited to work on further curriculum design and development, not testing or using, in partnership with the research team. We understood going into the project with students that we were coming in with some non-negotiables that would affect what types of work and what kinds of partnerships would be possible. For example, our responsibility to our funding agency (NSF) and resources allocated from NSF to do this work, both meant that we felt tied to designing curricular materials within the context of QM, and that these financial resources would allow us to spend more time on the project than would be possible for students. Conversely, as researchers, we knew we stood to benefit more than the undergraduate students who participated in the project. While the students were paid for their time, the researchers on the project were being paid a much higher hourly rate (as their salary). Papers written and the curriculum developed together would likely contribute to our, the researchers, continued funding and promotions, but not accrue direct benefits to the undergraduate student participants. These institutional and structural features constrained the kinds of decisions we tried to undertake in partnership with students, and what decisions were essentially made before student involvement.

\section{B. Recruitment and meeting structure}

Participants were recruited through flyers posted in the physics buildings and buildings that house QM-related research groups. Undergraduate physics majors also received an email detailing the project goals and structure. An initial meeting was held for students to learn more about the codesign project. This meeting was set up and facilitated by Ayush and Brandon, who would set up and plan six biweekly, $1.5 \mathrm{hr}$ meetings. While six undergraduate participants came to the first meeting, several participants left through the course of the project. All of these participants used he/him pronouns in referencing self and other participants. In the data presented in this paper, four participants in addition to Ayush and Brandon are present. They are pseudonymed Henry, Xavier, Cade, and Luke. Luke came into the meeting halfway through the presented data.

\section{Data collection}

The following data streams were collected during this codesign project: video and audio recordings, field notes and planning documents, and written artifacts. During the meetings, one camera typically recorded a room white board and another camera recorded the participants. Ayush and Brandon occasionally took field notes during the meetings. This practice lessened over the course of the six codesign meetings. Written artifacts included notes or work written during the meeting time (like post-its or scratch work), homework responses (electronically submitted to Ayush and Brandon), and pictures of white boards. These artifacts were collected, scanned, and then saved electronically.

\section{Analytical flow}

Soon after the codesign meetings had finished, our research team began content logging and transcribing the videotapes of the meetings. Our orientation was first to make sense of what had happened while the experience was fresh in our minds. For us, this sensemaking necessarily involved an orientation towards critical self-reflection. This orientation guided us in what patterns we saw across the data and what smaller moments or episodes we decided to select for closer and collaborative viewing [32]. Through connections across data streams (video, field notes, and planning-reflecting documents) and relevant literature on participatory design, we developed preliminary research threads that would help us make sense of our codesign project. One of these threads focused on participation in decision making around the process of the joint work. Once settling on this inquiry thread, we again went back and forth between individual and collective viewing of select moments in the videotape that revealed how decision making was undertaken by participants. This process involved writing analytical memos on how we were making sense of the interactions in the videotapes and using collaborative viewing periods to try out alternative explanations. We decided to focus on the episode presented in this article for several reasons: (i) several decisions were being negotiated by the participants in quick succession; (ii) triangulating the field notes and planning documents with the videotapes, we sensed that this episode was a moment when the facilitators (mostly Ayush) were attempting to engage students in the decision-making processes; and (iii) the rough, fraught nature of the episode that was apparent from first viewing the video made it interesting for closer study.

\section{E. Context for focal moment}

Plans for codesign meetings were typically drafted a few days before a meeting, by Ayush and Brandon, and occasionally another researcher, and were often based on reflections from the previous meeting(s). Students were 
not invited to take part in these meetings, but midway through the project were given access to the planning documents. Plans included activity prompts and sequencing of activities, assigning work to participants (including Ayush and Brandon) as homework, and guidelines for meeting facilitation.

In the meetings, Ayush and Brandon would decide how to proceed into or out of activities such as reading homework responses, having a group discussion, doing individual work, and working in small groups. These activity transitions often happened one of two ways, neither of which involved substantial collaboration with the undergraduate students in the group:

1) Ayush or Brandon initiated movement into the next activity without consulting anyone else in the group, saying something like "we were thinking we would...." This move may come with some explanation as to what the next activity was, and occasionally some additional explanation of why the group was moving onto the next activity. Or,

2) When Ayush or Brandon initiated a transition, the other might bring up some additional constraints (waiting for someone to show up, the amount of time left, etc.) that might affect how the transition to the next activity happened, which would be taken up accordingly.

Ayush's and Brandon's postmeeting reflections began to focus on whether the project and relationships, as they were unfolding, were resonant with their understanding of SAP principles and values. One concern was the decision to do all of the planning, structuring, and organizational work. This choice emerged from the recognition of the differential access to resources - the undergraduate students were paid at a lower hourly rate than the researchers on the project, ${ }^{1}$ and this project came on top of students' responsibilities towards school and work. However, it also was certainly a remnant and realization of roles and responsibilities Ayush and Brandon have historically taken towards students during their time at the University.

Midway through the project, there was an extended attempt to open up space for the students to more meaningfully engage in decision making around the codesign process. This manuscript aims to provide a detailed account of the complex and messy process of negotiating who was involved in the decision making and the interactional consequences of those negotiations.

\section{F. Interaction and microgenetic orientations towards analysis}

Tools and orientations from both conversation or interaction analysis [33-37] and microgenetic methods [38]

\footnotetext{
${ }^{1}$ Partly, this is due to institutional policies and typical guidelines for what is an appropriate compensation for students participating as research subjects in a project.
}

help us in describing these negotiations, including shifting stances towards participation and interactional positionings, in fine-grained detail in order to elucidate and uncover mechanisms driving these interactional negotiations.

Interaction or conversation analysis methods lend themselves particularly well to describing such processes of negotiation, as apparent in the stated goals of IA methods:

"[Interaction analysis methods] look for the mechanisms through which participants assemble and employ the social and material resources inherent in their situations for getting their mutual dealings done," (Jordan and Henderson, 1995, p. 42).

Our work draws on these methods (more details below) in order to describe how the participants interactively organize themselves and each other towards the mutual dealing of making decisions about the codesign process. Mapping out the mechanisms' driving and resources employed elucidates this complex process of negotiating participation, and reasons about how to potentially strive for different patterns of participation in future collaborations with students.

A microgenetic orientation $[38,39]$ guides us in thinking about the frequency and detail with which we need to model the interactional data in order to be able to describe the mechanisms driving this transitional process of negotiation. We have parsed the interaction into separate sections following the natural structure in the interaction. Choices on presenting some segments of the data from a microgenetic interactional level of analysis and some other segments at a mesolevel or summary-level description were made based on whether the interactional processes of negotiation in those segments were redundant and did not need significant reanalysis in order to be able to sufficiently describe the trajectory of the decision-making process.

\section{Analytical methods}

Our analysis and interpretations of the data take a threelayered approach.The first layer draws on tools from conversation analysis [33-37], the second layer takes a Goodwin-style approach to studying the contesting and negotiating work of the interactive organization of participation [34], and the third layer draws on Gee's discourse analysis [35]. Each layer of analysis and interpretation builds on the previous layer(s) and seeks to expand the sphere of context that provides support for our analysis and interpretation by making increased contact with additional layers of the ecosystem in which the interaction under close study lives. This layering approach allows us to make different kinds of conjectures about the power or force [35] behind the interactional patterns observed. In this section, we describe some of the tools, techniques, and orientations we draw on in the analysis, but without illustrating specific 
application within our data. In the findings section, we illustrate in detail how we have applied these methods to our data.

\section{Conversation analysis}

Tools from conversation analysis were used to model the sequential organization of the group's interaction in an extended episode of decision making ( $20 \mathrm{~min})$ around how to proceed with their collaborative curriculum design work. In particular, we drew on sequence organization, looking across sequential conversational turns in order to understand how, as a sequence, those turns accomplish basic actions [36]. The simplest organizational sequence in conversation is the adjacency pair, which is typically accomplished through two sequential turns in conversation and comes in particular flavors such as question answer, greeting greeting, or proposal acceptance or rejection [36]. Through sequence organization, we parse the extended episode of decision making as a string of smaller actions, which often happen to be smaller decisions. We then examine the co-construction of both these constituent actions and how one action follows from the previous.

Parsing the construction and stringing together of sequences in interaction also involves a particular focus on the organization of turn taking by participants, examining the degree to which opportunities for taking a conversational turn are available (or made available) to different speakers. We also examine how next speakers are selected, either by other selection or self-selection [40,41]. While sequence organization looks across several turns of conversation, a focus on turn taking points us to smaller grain sizes in conversation, focusing on places such as turn prefaces, turn ends, transition relevant places within turns [40], and the spaces between turns. Turn taking provides an explicit examination of which participants are involved within the processes of decision making, and the nature of that participation.

We narrowed into a fine timescale analysis of this particular episode because while the participants are engaging in explicit decision making around their joint work, even a cursory viewing of the episode revealed that negotiation by the participants was required for the participants to be able to figure out how to make the decision together. While the organization of trouble and repair [37] focuses on issues of hearing or understanding, trouble can also arise from differences in how participants are orienting to their own and each other's participation. In this case, repair can come in the form of negotiation of participation.

\section{Goodwin's analysis of the interactive organization of contesting and negotiation of participation}

Pulling together the analysis of sequential organization of the interaction-through sequence organization, turn taking, and trouble repair-we draw on Goodwin's analytical work on participation frameworks $[34,42,43]$, particularly Goodwin's conversation analytic approach to carefully revealing the contesting and negotiating towards participation in joint activity. Per Goodwin (and supported by the CA approach, as well), the interactive organization of participation is a joint achievement and requires active, on-going work by participants in interaction. This contesting and negotiating can occur along dimensions that are epistemological, affective, (un)cooperative, moral or judgmental, and or instrumental (material and physical organization of the interaction). For our data, the epistemological, cooperative, and instrumental dimensions ended up being most relevant in our analysis.

A principal idea relevant to our analysis is that the context of these focal moments is interactional in nature in two ways: (i) in the local, temporal sense in that each utterance or action occurs in the context of the previous utterance or action, and forms the context for the subsequent utterance or action, and (ii) the continuously accruing history of interactions the participants have had leading up to the moments of focus. In order to make sense of local interactive organization towards participationincluding organizing work that takes the form of contesting and negotiating - we then draw on our sense of this interactional history, as a way to understand the manifestation of the forms of interaction we observe (e.g., negotiation or contesting) and make conjectures about why we might see the forms of interaction we do (e.g., some participants contest interactive organization "proposed" by others because it breaks from interactional norms).

\section{Gee's discourse analysis}

We draw on Gee's conceptualizations of identities and discourses, in particular that certain identities gain their power to influence the course of action, through an authority derived from institutions $[35,44]$. In the case of this work, we focus on the institutional identities of professors and students which come with particular rights and responsibilities, and are consequently recognized or defined in relation to each other. For example, professors have a responsibility to teach their students, which comes with a right to conversational space in a classroom. Accordingly, students have some right to a learning experience and an associated responsibility to display their (partial) understanding to their professors so that their professor may orchestrate their learning experience.

In this layer of analysis and interpretation, we look for interactional patterns that recreate, attempt to recreate, or contest these institutionally sanctioned identities (professor, graduate student, and undergraduate student) and understanding how those patterns affect participation in decision making.

This layer expands the sphere of context to consider the historical, sociocultural context of the interactions so that 
we may make sense of institutionally sanctioned power that underwrites certain identities and discourses. Such interpretations allow us to reason about why certain forms of interaction manifest and then require significant work to disrupt.

\section{FINDINGS}

\section{A. Summary of findings}

In this focal episode, the codesign participants are discussing whether they should engage in a process of conceptual narrowing - whittling various (physics content) ideas that were generated in a previous conversation down to a "small" conceptual idea around which curriculum could be designed. Though a seemingly straightforward decision, negotiating whether the group should engage in conceptual narrowing interactionally cascades into many other decisions to be negotiated by the group.

Working through the process of conceptual narrowing brings up misunderstanding and misalignment towards how different participants will participate in decision making. These misunderstandings and misalignments require negotiation and repair in order for the group to move forward, with participants drawing on and coordinating various types of resources, including epistemology, status, content knowledge in physics, knowledge about curriculum design, personal experiences, and logistical information (time left in meeting and attendance).

In local moments, we see within, these processes of negotiation and repair, complex and messy interactions that contest and reaffirm-sometimes in quick succession and at times simultaneously-interactional and institutionally sedimented asymmetries in roles or positions of participants and their access to resources relevant to the decision making at hand. These interactions often serve to close off some decisions for participants (or frame them as closed off) in order to open up space for more participants to engage in the decision at hand.

Zooming out and away from the messy, complex back and forth inherent in these moments of negotiation-a process of interactional narrowing makes way for conceptual narrowing. That is, as participants negotiate participation in the process of conceptual narrowing, fewer choices become available to participants. Choices beyond whether or not to conceptually narrow, what comes next in the process, or what content the group should talk about. But very fundamental choices about how to engage and act in the space, including whether and how to voice opinions and oppositions, and at one point, even expecting silent participation by participants who came into the project as undergraduate students. This overall trajectory of interactional narrowing serves to crystallize the roles (through this episode) of Ayush and Brandon as primary deciders about how the codesign process should unfold, with other participants expected to partake in the decision making as heavily structured by Ayush and Brandon. These interactional patterns reproduce institutional asymmetries regarding access to resources and roles-particularly access to participation in decision making.

We now present our analyses of the focal episode. This episode occurred roughly 40 minutes into the fourth meeting (six in total) and is approximately 20 minutes in length. The episode has been divided into ten sections.

\section{B. Detailed analysis}

\section{Deciding whether the group should narrow positions as Ayush and Brandon as deciders of next steps and collapses the local decision-making space}

After the third codesign meeting, participants had been given the prompt: "Make a list of things that are difficult about angular momentum in quantum mechanics." The next meeting started with participants reading one another's written homework and then discussing this topic freely for about thirty minutes; reflecting on angular momentum and sharing personal learning experiences. We start out the transcript ${ }^{2}$ when Ayush makes a bid to engage in conceptual narrowing; selecting a small number of concrete ideas around which curriculum could potentially be designed.

1 Ayush: Cool. Um. Should we, should we try to narrow down to some little nugget of an idea that we try to, sort of like, flesh out some little bit of, like, [what it might look like? ((Gaze starts on Brandon, stays there, then scans around to other participants))

2 Brandon: //Um, yeah. As an administrative note, um, I just emailed Luke, and Luke said he's gonna be here, (.) like really soon, and I was wondering if we wanted to try(laughs) if that's the case, then we might break up into groups? But I guess we can, we can do this kind of narrowing and then break up into groups (Ayush: Yeah) and try to some [(?)-

3 Ayush: //We should do some narrowing, yes.

4 Brandon: Ok. (.) I think that's good. Others ((looks around)) heh? ((looks around table))

5 Xavier: Yeah.

6 Cade: Yep.

7 Henry: ((Nods))

Ayush's utterance starting with "should we" (L1) accompanied by his gaze scanning across the table suggests that Ayush was making a bid for the next action to be narrowing the space of ideas while directing the proposal towards the rest of the group. His turn forms the first pair part of an adjacency pair (L1-L4), a sequence composed of a few conversational turns which provide the basis for simple action in conversation. Examples include a greetinggreeting sequence, question answer, or proposal acceptance

\footnotetext{
${ }^{2}$ Transcript conventions can be found in Appendix A.
} 
or rejection [36]. A proposal is made by Ayush (L1), answered by Brandon (L2), and reaffirmed by both Ayush and Brandon (L3-L4). While the bid comes in the form of a question, it only articulates a single course of action and does not invite the group in divergent thinking around the next action. This further constrains the range of acceptable responses to Ayush's bid by making relevant a response that accepts or rejects the proposed action, and makes it less likely for people to propose alternatives.

Brandon's response (L2), the beginning of his turn coming in the form of an "insert expansion" [36] essentially interrupts the interactional activity of making and accepting or rejecting a proposal ("should we narrow") with information that is deemed relevant to the proposal. With his expansion, Brandon marks an administrative note regarding the attendance of a missing student. In this history of how roles and responsibilities were taken up within the group, this is a type of information that only Brandon has kept track of, while occasionally apprising the other group members of this information when Brandon deems it appropriate to the joint work at hand. Brandon's "administrative note" marks the presumed structure of the activity to come after "narrowing," and in doing so, the second pair part to Ayush's first (the proposal) emerges. At the end of his utterance, Brandon provides acceptance to Ayush's proposal to narrow.

Taken together the set of utterances (L1-L4), starting with Ayush's proposal on the next course of action, Brandon's making note of information that only he has access to, positioning that information as relevant to what he thinks the group should do next, and accepting Ayush's proposal regarding a potential next activity for the group, strongly reinforce the historical roles positioning Ayush and Brandon as the deciders of next steps (both within and before meetings).

Ayush's expansion to the sequence reaffirms that the joint course of action will be narrowing (L3). To which, Brandon provides his own expansion, a positive evaluation of this course of action "I think that's good," positioning Brandon and Ayush as on the same page with regard to subsequent action (conceptual narrowing). This turn functions as a sequence closing third [36] in that it frames the action proposed and accomplished through the previous sequence (proposal-acceptance) as complete, i.e., no future talk towards this action is relevant. In line 4, Brandon finishes his utterance by asking the other participants for their input on the decision that has been made, to which they voice their affirmation (L5-L7).

Through this co-constructed decision to narrow-as mostly led by Ayush and Brandon-negotiation of how group members should participate in the decision is also occurring. Most notably, while Ayush has positioned Cade, Xavier, and Henry as potentially relevant speakers in line 1 (those who could respond to the proposal of whether or not to narrow), Brandon forcefully positions himself as the one to respond to the proposal, both by talking over ${ }^{3}$ Ayush in the end of Ayush's turn and by making reference to consequential information that he has differential access to. Through this move, Brandon simultaneously contests the inclusion of Cade, Xavier, and Henry in the decision making as interactionally suggested by Ayush [34] and also positions himself as the uniquely appropriate other group member to take part in deciding whether or not to narrow.

It is worth considering what other responses to Brandon are reasonably possible when he asks the other participants for their input (L4). Conversationally, there would be significant interactional work to undo or reopen the proposal-acceptance sequence, resulting in delaying the group in moving onto the agreed upon action of conceptual narrowing. This organizational difficulty may be tied to a social norm of avoiding disagreement; it can be awkward to disagree with something that your team members have already decided upon.

Although, and most consequentially, this interaction occurs between participants in a very particular institutional setting - one in which membership within a certain identities [44] (professor) sanctions or underwrites certain kinds of power over people who are recognized as other kinds of identities (students). Work on the project has often played into these culturally and historically sedimented roles and relationships, with Ayush as a recognized faculty member, Brandon as a graduate student, and Xavier, Henry, and Cade (and later, Luke) as students. In line with these recognized, asymmetric roles, Ayush and Brandon have positioned themselves as having expertise related to curriculum design - the stated and shared goal of the project team and have (until this moment) kept the student members out of decision-making processes.

Would Xavier, Henry, and Cade feel sufficient epistemic authority to offer alternatives to conceptual narrowing, or to contest the course of action once explicitly decided upon by Ayush and Brandon? It seems possible but likely difficult due to the interactional and institutional force perpetuating the positioning of Ayush and Brandon as those who make decisions.

And so, at a microlevel we are demonstrating how the five participants co-construct ${ }^{4}$ two of them as having

\footnotetext{
${ }^{3}$ This move breaks typical turn-taking rules of selection in that, through gaze, Ayush has employed other selection (he has selected the students) but Brandon self-selects. Normally, self-selection is employed only when other selection is not [37]. The breaking of this norm flags this move as a place to look deeper into the interactional patterns around decision making; namely, the asymmetric turntaking opportunities distributed among group members.

${ }^{4}$ Here and throughout, our use of the term "co-construction" follows typical conversation or interaction analysis orientation, in that is a matter of analysis to show the manner in which an interaction is a joint achievement, and the nature of individuals' participation in that achievement. In this case, the nature of the co-construction is immensely asymmetric, with Ayush and Brandon providing most of the conversational input and the others providing post affirmations to their decision making.
} 
epistemic and decision-making privilege, with the other three co-constructed as having limited or constrained access to decision making in this space. In doing so, they reproduce and reify the roles that are traditionally available to these participants within many learning environments at the university.

\section{Trouble associated with what Ayush and Brandon mean by narrowing and why do it: team becomes stratified into groups with asymmetric access to interactional, epistemic power}

8 Ayush: Do you know what I mean- what we mean by

9 narrowing ((looking from Brandon to Cade))?

10 Cade: Yeah, I thi:nk (laughs) ((As Ayush turns to Cade, Cade turns away, mumbles and points to Henry))

11 Henry: Like, focusing on one concept?

12 Ayush: Yeah. ((quick, high pitched))

13 Ayush: Like some little tiny bit that we can focus down on and we can be like, Okay, if we want fellow students to understand this little tiny idea, right, like can we create a little, uhh like some set of (.) questions where if people were thinking collaborative around it. So the idea being that, you know, the setting you would want to imagine is that there are two or three students who are working on a set of questions and throu:gh working through particular sets of questions, they can clarify their understanding. Right, by engaging in debate, by engaging in, sort of like, discussions, trying to unpack. uhh, It isn't to write a textbook version. Which would be a different kind of a thing. Right, like somebody could say, "how do I write a really good explanation of this?" Right, so that somebody can read the explanation and understand it. But that's not the game that we want to play. We want to play the game of, like, how do we create certain kinds of problems or questions, that would help people understand, this concept better. Work with this concept better.

14 (10) ((Ayush and Brandon look around table))

Ayush makes a move to check for understanding (L8) and in the process repairs pronouns from "I" to "we," where "we" seems to refer to Ayush and Brandon, as evidenced through shifting gaze and subsequent interactional uptake of this turn. This repair leads to a cascade of interactional consequences in which the participants are organized into two groups, differentiated by positioning with respect to the courses of action being discussed and decided upon. One group - the students (Xavier, Cade, and Henry) - are recognized as potentially misunderstanding Ayush and Brandon. Ayush and Brandon make up the other group, the "we"; they are those in a position to check for whether their course of action is clear to the students. Consequently, Ayush's recruiting of Brandon through the repair of I to we also functions to lend epistemic authority to the action of narrowing. This accrual of epistemic power towards the notion of narrowing constructs an epistemic asymmetry of the two groups. It also means that interactionally, students must display their understanding-or lack thereof-for those with more epistemic power to then evaluate or remedy. The epistemic power asymmetry reconstructed in these moments reproduces local (on the project) and institutional patterns and creates interactional asymmetries in that now the students must perform for Ayush and Brandon.

Ayush's utterance ends with a gaze towards the students (L9). The pause, when next speakers have been selected, may indicate that what Ayush and Brandon mean by "narrowing" is unclear to the students. This interpretation is further supported by Cade's drawn out "I think" followed by laughter (L10). Cade turns to Henry; it may be that Henry can display a satisfactory understanding to Ayush and Brandon.

Henry's response (L11) rephrases aspects of the previous conversation, from Ayush's "tiny little nugget" to "one concept," which suggests some degree of understanding but it comes within a doubly hedged turn. The turn is prefaced with a "like" and is upwardly inflected at the end in a question. This epistemic distancing [45] interactionally opens space for the evaluation of his response to Ayush, where through lines 8-9, the participants have locally constructed Ayush and Brandon as those in a position to evaluate. Accordingly, Ayush provides the evaluation to Henry's rephrasing. His quick, "yeah," followed by an extended elaboration provides the sense that while Henry's response was close, it was not quite satisfactory.

Lines 8-13 follow an initiate-response-evaluate pattern, ${ }^{5}$ commonly found in educational settings $[46,47]$. There is a long pause, with Ayush and Brandon looking around the table at the students (L14). Interactionally, students again have the floor but the extended silence indicates there is some trouble-it is unclear to the students what they are expected to provide with their next turn. Institutionally, the initiate-response evaluation sequence has continued with the co-construction of the faculty-student dynamic in which very different performances are expected by faculty and students. Seeing the interaction through these identities, we can begin to better understand this source of trouble. It would be downright bizarre for a faculty member to ask students a question, evaluate the response, and then to remain silent while staring at the students. Such silence subverts the responsibility of the faculty member(s) to decide how to steer a conversation based on what knowledge students have displayed. And so the source of the trouble is likely not just a lack of understanding of what Ayush and Brandon are looking for, but the sequential co-construction of the student-faculty dynamic (L8-L13) and the immediate contestation of it by Ayush and Brandon (L14).

\footnotetext{
${ }^{5}$ This type of sequence organization is called a three-part interchange.
} 


\section{Trouble in the form of misalignment about who participates in the conceptual narrowing}

${ }^{6} 14$ (10) ((Ayush and Brandon look around table))

15 Cade: So did you guys have a particular concept in mind?

16 Ayush: We were thinking that maybe we take post-it notes and everybody writes down based on the discussion that we had and the list that we've created. Maybe zero down. And if we take a minute, and then we can exchange post-it notes and see what comes up.

17 Cade: Sounds good.

Cade's "so" (L15) marks a causal connection and acceptance of the previous turns of talk [48], initiating the upcoming course of action (narrowing). In doing so, Cade asks if "you guys have a concept in mind?" Cade is continuing to interactionally reify the group of Ayush and Brandon and their roles and responsibility that differentiate that group from the students, particularly making choices for the entire group. Cade's question can also be interpreted as a recognition that Ayush and Brandon might have further articulated (but as yet unshared) concrete concept in mind, a further narrowing of the field of decision making and further acknowledgement and reification of Ayush's and Brandon's recognized decision-making power that space.

Ayush chooses not to respond directly to Cade's request (L16), and instead proposes a post-it activity that everyone will engage in. In his utterance, Ayush's pronoun use of "we" seems to shift from referring to Ayush and Brandon to the entire group. In this shifting use of "we," Ayush reveals that while there is information that has been hidden from students and is now being revealed, what is revealed is a decision-making process, not the product of that process. While what the group (everyone) will narrow down to is now reopened as emerging through joint decision making, how that narrowing down will happen has been predecided by Ayush and Brandon. This interactional negotiation sequence simultaneously reinforces and contests the faculty-student stratification from the earlier sections and their differential, hierarchical access to knowledge and decisionmaking power that often come with it.

\section{How to engage in the conceptual narrowing activity is still unclear to some participants}

18 Brandon: I'll give myself three, see if I can get that far ((quietly, looking down)).

19 (7)

(Table continued)

\footnotetext{
${ }^{6}$ This line of the transcript is repeated for inclusion in the analysis of both sections.
}

\section{(Continued)}

20 Henry: So we're writing down three:, or, just different conc: epts or? ((looks to Brandon))

21 Brandon: So:, (.) I guess, so we're trying to narrow, right?

22 Henry: Yeah.

23 Ayush: Mhm.

24 Brandon: And so, (.) the way I'm thinking about this is I'm trying to write some kind of mini narrow goal or narrow conceptual goal which we can try to tackle by: by designing some, some, like, tutorial questions.

25 Henry: Okay.

26 Brandon: This style of thing that we were, that Ayush just introduced.

27 Ayush: Mhm.

28 Henry: Okay.

29 Brandon: Um, around, yeah. ((looks down))

30 Ayush: So, like- ((Brandon starts to speak))

31 Brandon: Go ahead.

Ayush: [Quick example is that, like, last time we were doing the angular momentum thing, right, like, there was a set of questions and the questions were essentially asking you to be like, "Oh, how would you think about the spinniness, and if you had to do a vector, where will you put that vector?" ((gaze scans across students)) Right ((gaze settles on Henry))? And so it was, the idea was that if people have different ideas around these and they talk about it, maybe they will clarify the meaning behind some of these things ((gaze scans across students)), right ((gaze settles on Henry))? It isn't to give a quick expla-, so something- there- there the core idea was how do we get people to visualize the vector or angular momentum for example. So that would be the core idea.

32 Brandon: //((looking down, writing post-its))

33 Henry: ((Nods))

Cade: Okay.

34 ((All look down))

35 (5 minutes)

36 ((people start looking around at each other))

Brandon initiates the post-it activity (L18), quietly remarking to himself that he will try to write three and muses whether "he can get that far." This move solidifies the previous framing that Ayush and Brandon do not yet have "a particular concept in mind," and will participate in the collective searching for one.

After a moment, Henry communicates his uncertainty about the activity as contextualized by Brandon's utterance (L20). Looking to Brandon at the end of the utterance positions Brandon as potentially having the clarifying knowledge Henry needs. However, instead of directly addressing Henry's query, Brandon reiterates the previously established framing of the task with some acknowledgements from Ayush and Henry that they are listening and on the same page (lines 22-28]. In his reiteration, Brandon takes Henry's contribution ("concepts") and shifts it slightly, calling it "mini" and "narrow," suggesting that the grain-size of the concept is important. Importantly, the 
language Brandon uses for "narrow goal" or "conceptual goal" is different from Henry's utterance that used "concepts"-which could potentially be intended as a correction, or a mismatch of ideas for what's being asked here. This might also be why Brandon is attempting a more comprehensive response to Henry than a briefer and to-thepoint response. The mismatch-if interpreted as difference in actual meaning between Henry and Brandon (trouble) and Brandon's attempt to align the interpretations of the task (form of repair). The repair also subtly highlights dimensions of differential access to knowledge in the group; Ayush and Brandon understand the educational intent ("conceptual goal") of the end product.

As Brandon seems to peter out, Ayush takes over the role of explaining to the students what is to be done and why. In doing so, Ayush elaborates the purpose behind the idea-seeking a bit more, and integrates this purpose with the nature of the concrete idea(s) being asked for in this task. This contribution, and in combination with line 13, functions to further solidify constraints of the end-product; questions that elicit certain kinds of responses and not others. In reaffirming these constraints, some decisions become closed off-what the end product will look like, what kinds of questions will go on it, how students are supposed to engage in it, and what counts as a "core idea."

\section{Contesting bids for participation leads to brief shifts in roles}

37 Ayush: Are folks... ((looking around at people))

38 Ayush: ((Quietly, looking to Brandon)) We only have half an hour left.

39 Brandon: Yep. ((Looking around to students)) Folks want to share out? (.) ((Looks around to students but no one meets his gaze.))

$40 \quad$ (.)

41 Brandon: I: will start. (laughs) Um, so my idea was, uhhh it's not very narrowed (laughs), um, but I worked a little bit in writing some stuff around Stern Gerlach apparatus for measuring spin. And I was thinking about how we could, possibly use that as a physical space to work towards a, like, an understanding of the uncertainty principle in that system. (.) Ummmm (.) something I was thinking about though as I was thinking about it was what, Henry, you said last time, where you were talkingwe asked the question about whether we needed to go from physical scenario to math or from math to a physical scenario. So I could also imagine trying to do one direction, the other, or trying to meet in the middle like you had said before.

42 Brandon: ((turns to Xavier)) For context, we had this big long discussion. I can, we can try to catch you up later.

43 Ayush: Mhm.

44 Brandon: That's all I had.

After about 5 min of relative silence, with people quietly writing on post-it notes, the students start to wiggle in their seats and sit up straighter, potentially signaling to Ayush and Brandon that they are done with their work. Ayush engages the group with an open "are folks..." which seems like both a check-in but also a request for some kind of input. Ayush is met with silence. Ayush and Brandon quickly conference, between themselves, about the time left in the meeting, and in recognition and response, Brandon pushes the group of students again for input.

It is worth considering why Ayush and Brandon so forcefully insist that the students share first if everyone has participated in writing post-its. The utterances so far work to position Ayush and Brandon as facilitators of the group. It may be that, in part, the insistence from Ayush and Brandon that the students share first comes from culturally accepted role of facilitator as making bids for others' input and avoiding dominating the space with one's own ideas.

These moves by Ayush and Brandon fall in line with historical patterns for the group's function where Ayush and Brandon have access to the plans for the meetings and keep track of the time left in the meetings. Coordinating between these two threads of information well positions them as those responsible for initiating and closing activities.

Here, we see students contesting how Ayush and Brandon are orienting to the unfolding activity through their silence and non-engagement, effectively renegotiating how the action will proceed-Brandon takes up the turn and shares out, possibly marking some tension of the contesting and renegotiation in the form of the trouble (double rejection) and repair (Brandon shares out). Here, the trouble is in the form of the students rejecting bids to share is repaired by facilitator Brandon sharing out his idea. In doing so, at least momentarily, Brandon takes on the position of a participant instead of facilitator or coordinator. But the shift seems short lived as Brandon turns to Xavier (L42), and remarks that although Xavier is likely not on the same page as everyone else, now is not the time to catch him up.

\section{Sharing out ideas ${ }^{7}$}

Following Brandon's sharing out, the other participants share their ideas from the post-it activity, starting with Cade. There are some hedges along the way but this portion of conversation is markedly different than what has occurred previously. Strikingly, in this segment, there are no significant troubles in the forms of misalignment or misunderstanding. What is significant to note during this portion of the conversation is the ease with which the students respond to each other, further supporting previous interpretations that some instances of silence in previous episodes were an indication of trouble.

\footnotetext{
${ }^{7}$ This portion of the transcript has been moved to Appendix B for brevity.
} 


\section{How should we proceed? Negotiating how to move forward towards conceptual narrowing after post-it activity}

62 Ayush: How should we proceed ((gazes across table))? With this thing? It feels like there's a bunch of different ideas on the table.

63 Brandon: Ummmm, we could, we could vote ((glances to Cade, Ayush, Henry in succession))? Heh heh um. We co:uld, (.) I don't know.=

64 Ayush: Let me see. (.) Right. Well it also seems there's other- well Brandon and Cade, you folk- both of you were talking about the uncertainty principle, and trying to make sense of the uncertainty principle, right? A:nd Henry and I were both thinking around, simultaneous versus sequential measurement, right? Um, (.) Xavier what you said about observables- observables, right, and why some things would commute or not, uh, (.) I'm trying to think. I'm not $100 \%$ sure, but it could have resonances with either one of these two groups, right ((glances to participants as he references their ideas)). Um ((gazes lands and stays on Brandon)). But we could divide in two small groups and do some more focused work.

65 Brandon: Yeah. I like the idea of dividing. Um, do we want to, 'cause we had talked before, um that we thought it would be more beneficial if it was the same topic (looks to Ayush)).

66 Ayush: Yeah. But uh, yeah, so what do, what do folksyeah.

$67 \quad(12)$

68 Brandon: What do you think? ((looking around at Henry, Xavier, Cade))

69 Ayush: What are the things on the table, let me (?) ((gets up to write on the board))

Ayush opens up to the group an important question about the process of their work; "how should we proceed?" (L62). While what Ayush means by "this thing" may be unclear, the utterance ends with "there are a lot of ideas on the table" which suggests that Ayush is viewing the activity of narrowing as incomplete. Brandon's quick response to Ayush's question to the group comes with a proposal to vote, but the discourse also has some epistemic distancing qualities to it; accompanying laughter, it seems to be framed as a joke, and ending with "I don't know," [45]. This distanced response might suggest that Brandon is unsure whether this will be an acceptable response for Ayush, but his glance across the table interactionally positions Henry and Cade as participants that can address whether this is an acceptable course of action.

Ayush subtly rejects Brandon's proposal by not engaging with it. Instead, Ayush takes on a facilitator-type role in revoicing the post-its of the other participants. While this utterance maintains, in some ways, the interactional relevance of all participants (through referencing their ideas and looking to them as he speaks), Ayush's utterance also simultaneously groups the ideas and participants into two, suggesting that the next course of action could be "divid[ing] into two small groups and do[ing] some more focused work." The preface of "but we could" suggests that this course of action is open for discussion but the lack of inflection seems to suggest otherwise. If interpreted as open to discuss, context might suggest that all participants are relevant next speakers. However, Ayush's gaze landing and staying on Brandon through this suggestion interactionally positions Brandon as the one to participate in deciding whether or not. Additionally, another quick response by Brandon which voices his approval of the action (dividing) and references a private conversation between Ayush and Brandon in which they had decided that working on the same topic would be better. While the evaluation of this course of action is revealed, the reasoning behind it is not. This could easily send the impression that this moment has already been planned for the others, with Ayush and Brandon knowing what is a better course of action. And so, when Ayush and Brandon then attempt to ask for input from the other participants, (L66, L68, and L69), it is likely unclear what is available for others to choose from and whether they will make the "right" choice, based on criteria that they have not participated in constructing, but apparently Ayush and Brandon have access to.

Over these few turns, through gaze, quick responses to each other, and an utterance that frames the suggested course of action as already decided upon, Ayush and Brandon reproduce interactional patterns that frame themselves as those who decide what the participants, given their unique insights. However, there are also simultaneous and interspersed interactional moves to position the students as expected to give some kind of input into this decision making. This likely sends complex and contradictory messaging by Ayush and Brandon to the other participants. Especially given that as Ayush is asking the group to participate in deciding how they should proceed in the codesign process, the extended negotiation of that participation is continually closing things off to the others (e.g., that they will work in groups, that narrowing down to a topic is incomplete, that there are two ideas to choose from.) while revealing that there are also hidden and predetermined criteria for the process.

In this interaction, Ayush and Brandon are maintaining the relevance of participants who have not historically been engaged in the decision-making processes through simultaneously framing other aspects of the process as decided (two ideas to choose from, the participants will split into groups, groups working on the same idea). In subsequent sections, we see some decisions (choosing from two ideas and splitting into groups) are solidified, the other (working on the same idea) becomes reopened for additional input for other participants. 


\section{Ayush frames decision to be made by all participants: picking one of two conceptual ideas}

70 Cade: Whether we should be in groups or do, all work together?

71 Ayush: Yeah. The two ideas right now are, (writes on board) one is simultaneous, and, right like and how are different ways we approach it. Right, whether we ask students to do that, et cetera et cetera.

72 ((L knocks on the door and Brandon opens it for him.))

73 Ayush: And the other idea was to look at uncertainty principle ((writing on board)) and angular momentum. Right, now uncertainty principle in the, in the abstract. Right, kay? Those are the two ideas. Mmm.

74 Brandon: I'm fine with thinking about either.

75 Ayush: That's what everybody's gonna say.

76 Brandon: Yeah. I'm just sayin'.

77 Ayush: And that doesn't resolve our thingies. Um. (.) Which?

In line 70, Cade responds to Ayush's and Brandon's requests for input, asking whether the decision to be discussed is whether they work in groups or all together, potentially reopening different structures for joint work, as it seems the pathway forward is presumed to be working in groups. However, Ayush's seeming misunderstanding of Cade functions to reject ${ }^{8}$ Cade's framing of the decision to be made as choosing between the options of working together or in groups. Instead, Ayush reiterates that the choice is between the two conceptual ideas he had surmised earlier.

Through the process of negotiating who is involved in decision making and how; the interactional space that Henry, Xavier, and Cade are expected to act within is incredibly complex and messy. The quick back and forth between Ayush and Brandon frames and reproduces decision making as only between them, but the content of those utterances strongly positions other participant input as expected. However, the input expected becomes fairly constrained or dictated. Ayush is suggesting that all participants need to participate to resolve the current issue (deciding between two ideas), and that a nonpreference (e.g., L74) is not acceptable because it does not work towards Ayush's framing of what counts as a resolution.

In the following bits of interaction, the group continues to engage in a process of interactional narrowing in order to negotiate their way through the task of conceptual narrowing, thereby making continuously fewer ways of interacting and participating in shaping the processes of the decision making available to student participants.

\footnotetext{
${ }^{8}$ This is not reopened by any participants and they move forward interacting as if working in groups is the presumed course of action.
}

\section{Negotiating how to decide between the two conceptual ideas}

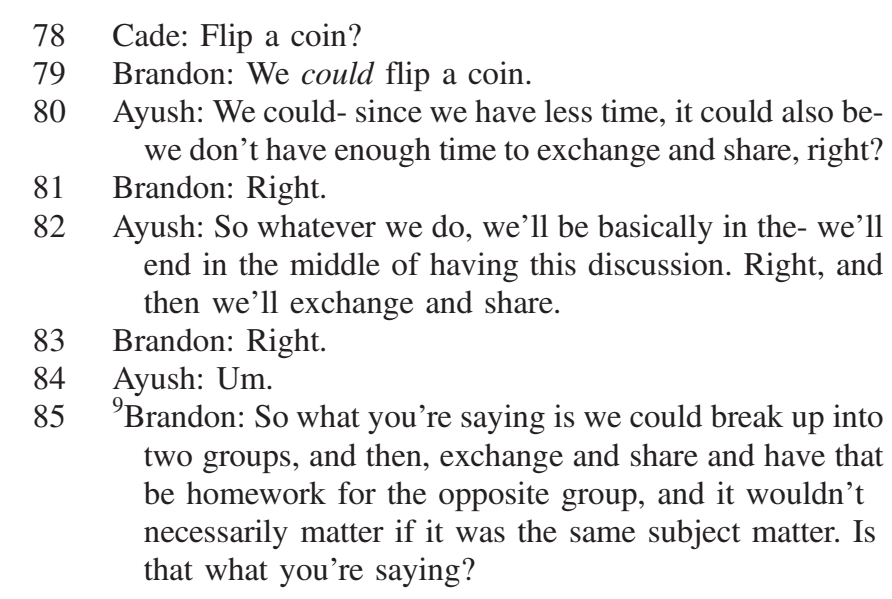

After the extended negotiation around involvement in the decision-making process, Cade suggests a path forward, "flip a coin?" But Cade's suggestion is met with reference by Ayush to the recurring tension of time left in the meeting. This again leads to an extended back and forth between Ayush and Brandon about the logistics of the next activity, but the logistics are consequently related to some criteria predetermined by Ayush and Brandon about what counts as acceptable group work. Revealing more "hidden" criteria calls into question how well others are able to actually participate in making this decision.

Brandon's apparent reiteration of Ayush's concern and what that means for how to proceed with the next activity comes with some new information; there will be homework for Cade, Henry, and Xavier after this meeting. Locally, this move actually opens back up space in the local moment for what's available, contesting the collapsing implications of Ayush's turn and renegotiating what is available for Henry, Xavier, and Cade to choose from in the moment. However, the potential reopening of pathways forward, albeit marginally, imposes "homework" on the participants if they were to choose the option reopened by Brandon. It is important to note that two things about Brandon's utterance: (i) Brandon was the participant who had suggested earlier that the groups should work on the same idea based on predetermined criteria, and (ii) Brandon is realigning himself (as he has in all past meetings) as a participant who is capable of assigning homework to other participants. The confluence of these aspects of Brandon's

\footnotetext{
${ }^{9}$ This utterance seems discontinuous with the conversation. It may be that this is simply how Brandon is interpreting in Ayush's utterance. Or it may be that Brandon is trying to read "between the lines" of Ayush's dilemma, or trying to anticipate where Ayush is going. Despite the discontinuity, we stick with the interactional function of this utterance.
} 
utterance further crystallizes his role as structural decision maker, one who is capable of opening and closing local decisions to other participants, which in this case comes with a price (homework).

\section{A forced choice: will groups work on the same conceptual idea or different conceptual ideas?}

Ayush: the advantage of doing separate ideas is just that groups are just doing whatever they want to do, right? Um, so li- maybe, maybe vote on this, same versus different. And, and we just, there's a forced choice. We have to, cus all of us have to take a, take some stance towards it, right?

87 Brandon: So, same or...

88 Ayush: Same or different, and that's a forced choice. Option 1, same, heh option 2 different. And if it is the same, then we'll have to pick one of those two, and then that's okay, because if we don't do one today, we'll do one [next time.

89 Brandon: //Right right. So, option 1 is same, and option 2 is different. (Ayush: Different) As in we are gonna do 1 or we're gonna do 2 at the same time

90 Ayush: Yes.

91 Brandon: Right, okay. So maybe just everybody puts their fingers up? To represent their vote?

92 Ayush: Yeah. Are we gonna proceed with these sequentially or [simultaneously.

93 Cade: //heh Oh god. (laughs)

94 Ayush: (laughs) So, um, (.) how many people for sa:me? (Brandon: ah-) Is that, is that what, how [you wanted to do it?

Brandon: //No, I was saying, everybody just put their fingers up, ahhh like, on the count of three, so everyone decide whether (Ayush: Ahhh) you want same or different, (Ayush: yeah.) and then either go like this ((puts one finger up)) or go like this ((puts two fingers up)).

96 Cade: Okay, so same different ((motions option with fingers)).

97 Ayush: Same different ((motions option with fingers)). Same different ((motions option with fingers)).

98 Brandon: Yes.

99 Ayush: Oh okay, perfect.

100 Brandon: Okay, so everyone decide. ((Exaggerated look across table)) Okay, 3, 2, 1.

101 ((Everyone puts fingers up, laughs))

102 Brandon: The sames have it. ((Laughs)) (Ayush: Okay.) Okay, so then we have to decide.

103 Ayush: We have to decide which one.

104 Xavier: Uncertainty?

105 Ayush: Hmm?

106 Xavier: Uncertainty principle?

107 Cade: I guess (?)

108 Ayush: Are you okay with that Henry?

109 Henry: Yeah.

110 Ayush: Yeah, I'd be okay with that too.

(Table continued)

\section{(Continued)}

111 Brandon: Okay, so do we just want to divide like this? ((gestures line across table))

112 Ayush: Sure.

113 Brandon: In two groups. (Ayush: Yeah.) Um, okay and we're each working on the uncertainty principle, (Ayush: Mhm.) specifically around angular momentum, and we're gonna try to come up with some prompts. ((looks around)) Great. ((Turns to Xavier and Cade)) Um, I think, let's go over to this table. That way we can separate audio a little better between the two groups.

Ayush takes up Brandon's opening of a new potential path forward that the group can choose from; groups can work on the same concept or different concepts. In doing so, Ayush contextualizes this choice in terms of pros and cons, which harkens back to Brandon's comment in L65 which referenced a private conversation between Ayush and Brandon about what they had anticipated would be "more beneficial." While in some ways participants have more choices available, things are continuing to become more closed off in that they are now expected to take part in a "forced choice."

With recognition and affirmation from other participants (L96 and L101), a quick negotiation between Ayush and Brandon settles how the other participants will make their choices visible to the others. While there seems to be some misunderstanding between Ayush and Brandon about how exactly this will happen, they settle on a process suggested by Brandon- everyone will simultaneously raise one finger or two, depending on their choice. While Brandon has contested the decision-making process suggested by Ayush, the process he has suggested instead closes off opportunities for others to do the same contesting workthrough suggesting an instantaneous decision-making process (vote counting) which effectively silences other participants in their participation in the decision making.

Through a vote orchestrated and tallied by Brandon, the group has decided to work on the same concept in groups. Ayush presents the next decision to be made: which topic from the two available (uncertainty principle or angular momentum). Xavier proposes the uncertainty principle to which the others, through facilitation by Ayush, quickly agree. And with Brandon showing how the participants should split, with Ayush's affirmation, the groups move into the next activity with directions from Brandon.

This episode completes the now-crystallized pattern of negotiating participation in decision making when some participants, Ayush and Brandon, are positioned as having more say and understanding about the decisions being made. Involving others in these decisions has come at the expense of Ayush and Brandon closing other decisions off, while continually positioning themselves or being positioned as participants who can make those decisions, and have relevant, sometimes hidden, insight into those processes. 


\section{SUMMARY OF ANALYSIS}

TABLE I. Summary of choices.

\begin{tabular}{|c|c|c|c|}
\hline Section & Decision & $\begin{array}{l}\text { How space related to that decision is } \\
\text { open or closed }\end{array}$ & Roles \\
\hline \multirow[t]{3}{*}{1} & \multirow[t]{3}{*}{ Whether or not to narrow topics } & Ayush opens up space & Ayush and Brandon positioned as \\
\hline & & Ayush and Brandon close off space & $\begin{array}{l}\text { curriculum design experts, having } \\
\text { decision-making power }\end{array}$ \\
\hline & & $\begin{array}{l}\text { Cade, Xavier, and Henry accept the } \\
\text { decision }\end{array}$ & $\begin{array}{l}\text { Cade, Xavier, and Henry positioned as } \\
\text { students with limited decision-making } \\
\text { power }\end{array}$ \\
\hline \multirow[t]{4}{*}{2} & \multirow{3}{*}{$\begin{array}{l}\text { What is meant by narrowing } \\
\text { topics }\end{array}$} & Ayush opens up space & Ayush positioned as knower evaluating \\
\hline & & Cade, Henry, participates & Henry's response \\
\hline & & Ayush evaluates Henry, closing off space & $\begin{array}{l}\text { Cade, Xavier, and Henry positioned as } \\
\text { student }\end{array}$ \\
\hline & $\begin{array}{l}\text { Broader trajectory (the purpose } \\
\text { of narrowing and the activity } \\
\text { that will result) }\end{array}$ & $\begin{array}{l}\text { Ayush and Brandon (through Ayush) } \\
\text { closes off space by stating the purpose }\end{array}$ & Ayush and Brandon positioned as authorities \\
\hline \multirow[t]{2}{*}{3} & What topics to pick & Ayush opens up space for all to contribute & $\begin{array}{l}\text { Cade positions Ayush and Brandon as } \\
\text { authorities, Ayush rejects that position }\end{array}$ \\
\hline & How a topic will be chosen & $\begin{array}{l}\text { Ayush closes off space by revealing the } \\
\text { process decided by Ayush \& Brandon }\end{array}$ & $\begin{array}{l}\text { Reinforces Ayush and Brandon's position as } \\
\text { authorities }\end{array}$ \\
\hline \multirow[t]{2}{*}{4} & Picking topics & $\begin{array}{l}\text { All contribute, with the directions } \\
\text { clarified by Brandon }\end{array}$ & $\begin{array}{l}\text { Brandon (and recruiting Ayush) positioned } \\
\text { as guiding activity }\end{array}$ \\
\hline & Broader trajectory or purpose of & Ayush and Brandon close off space by & Ayush and Brandon positioned as authorities \\
\hline
\end{tabular}

$5 \quad$ Sharing topics reinforcing the purpose and what the end-state will look like

Ayush opens up space for all to share

Cade, Xavier, and Henry reject the opening by not sharing

Brandon shares out

$6 \quad$ Sharing topics

All group members share

7 How to narrow from set of topics

Ayush opens up space

Ayush and Brandon name two options

Ayush and Brandon invite input

Picking between two prescribed ways of narrowing

Picking between two topics

Cade makes a bid to discuss Ayush closes bid by proposing new bid

Ayush opens up space

Ayush and Brandon positioned as facilitators Brandon positioned as a participant

Students position other students as participants or collaborators

Ayush and Brandon positioned as facilitators, who are knowledgeable about

Cade, Xavier, and Henry positioned as giving input

Ayush and Brandon positioned as facilitators Cade, Xavier, and Henry positioned as giving input (but with narrower acceptable inputs)

$9 \quad$ Picking a process for discussing ideas and sharing

10 Picking between working on one idea or two ideas

Picking a topic to focus on

Ayush and Brandon discuss splitting into groups

Ayush and Brandon open up space for students to decide between one idea or two ideas through a vote.

Cade, Xavier, and Henry Vote

Ayush and Brandon open up space for students to decide which idea to focus on

Picking a process for discussing ideas and sharing

Ayush and Brandon assume they will be split into two groups

Ayush and Brandon positioned as managing logistics

Cade, Xavier, and Henry positioned as deciding on whether to discuss either idea as both

Cade, Xavier, and Henry positioned as contributing to conceptual narrowing

Ayush and Brandon positioned as authorities in terms of discussion structure 


\section{DISCUSSION}

\section{A. Physics curricular design that engages students as partners should carefully document interactional processes to better understand, and continually work towards, more equitable partnerships}

Students have traditionally played essential roles in curricular design processes in PER. Data of students' reasoning have helped the field to design materials that address content-related difficulties commonly faced by students, take into account students' expectations about learning physics, assess the effectiveness of curricula, and inform revisions to curricula [1-4]. More recently, a few others have taken on SAP orientations and are working to invite students into meaningful decision making in educational design processes, e.g., Refs. [10,22,49].

SAP researchers in other contexts have highlighted the positive outcomes associated with incorporating student voices into design processes. However, the ways in which SAP has been enacted in physics curricular design has been largely understudied. A careful study of challenges associated with instantiating SAP curriculum design can help the field better understand how student voices can be incorporated in, or shut out from, products designed through these processes. In particular, this work helps carefully illustrate the challenges associated with attempts to restructure roles and relationships.

\section{B. Microgenetic analysis helps us project alternative facilitator moves that could potentially disrupt existing hierarchical codesign processes, rather than think of the reproduction of these hierarchies as foregone conclusions}

Our analysis, as summarized in Table I, illustrates how the discourse between participants served to reify institutionally sanctioned roles. This could lead to a potential interpretation that, given the asymmetry between participants, the reproduction of institutionally recognizable hierarchies was a foregone conclusion. Our claim, however, is that such reproduction was emergent through the collective activity of the participants in the focus group, the site of contact between the micro-interactions of the participants and the macro-institutional discourses [29,44]. This is not to discount the role and function of the hierarchies and the associated discourses, but rather to create a more nuanced interpretation of how the interactions function at the micro-, meso-, and macroscales simultaneously [50]. In this section, for the first and the seventh segments of the data, we engage in some gedanken-style argumentation of imagining new sequences of participant interactions to illustrate that the micro-interactions, even in this space, held the potential to alter what decision making related opportunities were available to participants.

Consider, for example, the segment of the transcript that we open with. While L1 has the form of a question, lines
L2-L4, function together to close the decision-making space. What if the responses to $\mathrm{L} 1$ had been different? We can imagine that the interaction would have played out differently had there not been the need for an administrative note at that point. Or, consider the following hypothetical dialog sequences (the utterance that is imagined is marked by an asterisk):

1 Ayush: Should we, should we try to narrow down to some little nugget of an idea that we try to, sort of like, flesh out some little bit of, like, [what it might look like? Are we ready to narrow?

$2 *$ [Someone]: What does that really mean?

Had the dialog played out this way, it could have opened up the space for establishing shared meaning of the activity, ameliorating some of the asymmetry between participants with respect to knowledge of the task. Or, maybe if Ayush had asked, "Before we proceed, can we try to establish a shared understanding of the task?" Or, instead of proposing to "narrow down to some little nugget of an idea," if Ayush had proposed that the group should collaboratively come up with a procedural plan for how the curriculum development would take place. All of these alternative moves would have opened up the space for "students" to access a bit more of the decision-making space.

In the seventh segment, Ayush's and Brandon's utterances in L62-L64 serve to establish the next step as narrowing down to a smaller set of ideas which can then be pursued for curriculum development. An alternative approach could have been for Ayush and Brandon to pose starting with any idea on the table, to try out what developing curriculum around that idea would look like:

*Ayush or Brandon: let's try on an idea, and if it doesn't work, we can try other things.

That could have made the task of choosing one concept to pursue less weighty, by explicitly allowing that their initial choice could be later changed. We also wonder if the turn of events, locally in that segment, might have been different had the silence in L67 been allowed to persist. That silence, in some sense, signified that participants other than Brandon and Ayush might be struggling with what to say, or that Ayush's or Brandon's talk about narrowing, grouping, etc., was not particularly clear to the other participants, or that they might be unsure of whether and how much they have the power to shift this process. These uncertainties, if given a chance for exploration at that moment, could have locally produced opportunities for students to participate in the structuring of the activity.

We do not mean to suggest that any small interactional move by itself can transform what roles are available to the participants in the interactions. But just like in our analysis, where we have shown how the micro-interactions between 
participants function to reproduce institutional discursive patterns and the institutionally sanctioned hierarchy of roles, alternative micro-interactional "nudges" could also accrete to shift the available subjectivities in the focus group. In this section, we have tried to imagine what some of the nudges might have looked like.

\section{Self-critical, microgenetic interactional orientations help guard against "romanticized" and reductionist views of the processes of partnership}

Literature around SAP work often touts benefits and positive outcomes [7]. In a review of SAP literature, Mercer-Mapstone and colleagues found that $92 \%$ of papers included in their study reported positive outcomes for students. The outcomes included higher quality of teaching and increased communication between students and faculty. Some researchers also discuss the potentially "transformative," democratizing nature of this work $[5,7,9,51]$. These reveal a shift towards focusing on education processes or systems, and highlight the potential of SAP to drive cultural shifts away from hierarchical processes towards more egalitarian processes, where faculty and students are truly equal partners. This literature creates the sense that partnerships, and the processes through which curricula are developed, are meant to be fully democratic processes where all voices are equitably heard and valued.

Practical recommendations from SAP literature are in line with this positive-outcome, process-oriented, and transformative focus. These recommendations tend to be coarse grained in nature and focus on the values of partnership. For example, some work differentiates potential sites for engaging students as partners [12,52]. These sites include areas such as curriculum design, assessment, scholarship of teaching and learning, and discipline or subject based inquiry [12]. Where partnerships are based on the values of reciprocity $[52,53]$, mutuality, and complementarity [54]. Whatever the chosen context of the partnership may be, "the common thread is a repositioning of the roles of students and staff in the learning endeavor, grounded in a values-based ethos" [7] (p. 2).

Together, this literature may inadvertently present a "romanticized," reductionist sense that partnerships involve homogeneous engagement of all participants in a democratic process. While some work, e.g., Refs. [29,51] describe some troubles, especially with respect to reproduction of hierarchical roles and norms, detailed accounts of what that reproduction might be like are missing. Moreover, we argue that partnership involves a complex web of a multiplicity of decisions and dimensions of agency. Coarse-grained descriptions of partnership can often be reductionist, focusing on surface features such as equal talk time, and participation in a vote. It is important to move beyond these simplistic operationalizations of "partnership" that treat student voice as students having agency and treat students voting as students having power. Cook-Sather [55] does caution against the impositional potential of student voice work, in which researchers bring expectations about students' participation roles in these projects. However, Cook-Sather's theoretical account would be complemented by work that provides grounded accounts of what these kinds of interactions and issues of translation look like. As is visible in our analysis, in the continual path of working towards these visions our partnership has many stumbles along the way, and is marked by constant trouble and repair.

It is tempting to be drawn into seeing and talking about these design processes as transformative, but we think that such perspectives miss the ways in which these processes can also enable reproduction of existing power structures. Mercer-Mapstone and colleagues [7] note that while negative outcomes of partnerships are less frequently reported than positive outcomes, the most common negative outcome reported reproduction of hierarchical power structures.

In this focal episode, the facilitators had a transformative intention in mind when attempting to renegotiate participation in decision making around the codesign process. And the facilitators left the codesign experience feeling more highs than lows, immediately recognizing the moments that they wanted to celebrate. Between meetings, they also discussed concerns about how they might elicit greater participation in decision making from students and ways in which they were reproducing hierarchical roles. It was through this inquiry process - first with the recognition that we also needed to bring a self-critical orientation to analyzing our experiences, but also the microgenetic, interactional methods - that enabled us to see the complex mélange of contesting and reproducing norms, roles, and relationships. These microgenetic methods help in highlighting the micro-mechanics of conversation, opening them up for tinkering, so that, as a field, we can continue to work towards reciprocal, mutual, and complementary partnerships [54] and away from the impositional potential of partnerships [55]. The fine-time scale analysis makes the trouble and (sometimes unsuccessful) repair visible to us as researchers, opening up doors for corrective action, either during the partnership or to learn from one and apply to another.

\section{Future work: microgenetic analysis of shared epistemic agency in groups}

There is growing evidence that effective and productive collaboration between people towards generating or designing a shared object requires collective cognitive responsibility from the people involved-a "shared epistemic agency" [56,57]. Building on Scardamalia's work [57], Damsa et al. [58] operationalize shared epistemic agency in terms of actions that individuals take within a group that enables the group to make progress towards the production 
of shared knowledge. They define two dimensions to the shared epistemic agency of a group: (i) an epistemic (or knowledge related) dimension, involving actions such as identifying problems, collecting new information, and sharing ideas and knowledge, and (ii) a regulative (or process related) dimension constituted in actions such as setting common goals, creating a joint plan of action, and monitoring object progress. Damsa et al. articulate ways in which both epistemic and regulative actions are necessary for effective production of a shared knowledge-object through collaboration [58].

We see resonances with this framework in our data and analysis, where students had the agency to participate in sharing ideas for physics topics for curriculum design (which we can think of as the epistemic dimension of the partnership) but had limited access to processes by which these ideas are shared, selected, and made progress on (which we can think of as the regulative dimension of the partnership). From this perspective, most of the actions tied to regulative agency were carried out by Ayush and Brandon. Further, Ayush's and Brandon's attempts to create space in the epistemic dimension simultaneously functioned to close off access to the regulative dimension, illustrating that discursive actions simultaneously impact the epistemic and regulative dimensions of shared epistemic agency. This might suggest the need for attending to both the epistemic and regulative dimensions of agency when designing learning environments to engender students' agency. Given interest in physics education research in the construct of agency $[59,60]$, it might be promising to look at the intersection of microgenetic, interaction, and discourse analysis methods and notions of agency in learning environments.

\section{CONCLUSION}

This article adds to an emerging line of scholarship in PER that engages students as partners in curricular design. Challenges associated with facilitating interactional processes in which students play meaningful roles in decision making are largely understudied in the context of PER, and SAP work more broadly.

Our analysis of the focal episode unpacks the complex process in which five participants decide on a small set of concrete QM ideas on which to focus subsequent curriculum design activities. Accomplishing the joint work of "narrowing" the conversation down conceptually required the group to decide upon and accomplish smaller, constituent actions along the way: whether to narrow, how to narrow, what topic to pick, and how to discuss the picked topic.

Microgenetic, discourse analytic methods enabled us to turn a fine-grained, self-critical eye on how our project enacted SAP principles. Through this analysis, we showed that attempts to open space in decision making involved extended, complex, and at times subtle, negotiation and contestation of participation. In order to engage in conceptual narrowing, our analysis highlights how the group's joint pursuit of conceptual narrowing also functioned to limit the decision-making space available to the students in the group. Opening up space for participation in some decisions came at the expense of others, with students ultimately being shown how to choose from a small number of prescribed choices. Collectively, the group reproduced the historical, hierarchical forms of decision making and roles available to faculty and students.

Our self-critical, fine-grained approach allows us to tinker with the interactions as they played out and imagine alternative interactional moves that could have potentially opened up more opportunities for students to participate in decision making around how to proceed. Our analyses also push back against reductionist and "romanticized" notions of partnerships by demonstrating some of the complexity of student agency and power in these partnerships. We hope that this would support our research group, PER, and SAP practitioners to continue to work towards more equitable partnerships with students.

\section{ACKNOWLEDGMENTS}

This work is supported by NSF-DUE 1625797. We thank the students who participated in our study. We thank Donna Hammer, Tom Gleason, and Education Services in the department of physics at University of Maryland, College Park, for help with recruitment. We thank Andrew Elby for giving feedback analysis over the entire course of this thread of research and his continued mentorship of all the authors. We thank Tara Brown for initial consultations with us on partnering with students. We thank Angela Little, Chandra Turpen, and Jennifer Radoff for their early support in the codesign process. To determine authorship, the research team assessed which team members contributed to different activities involved in developing the manuscript, then weighed these contributions against each other. All authors contributed in significant ways to this work. E. R. S. led this research thread in terms of intellectual merit as well as managing the process and analytical flow. E. R. S.'s most significant contributions included developing the principal arguments, literature review, developing and refining data selection and methods and analysis, writing, and articulating the implications and conclusions. A. G. and B. J. J. contributed to the design and facilitation of the codesign meetings. A. G. also contributed to data collection, processing, and transcription and participated in analysis. G. M. Q. contributed to the literature review, data analysis and writing, and articulating the implications and contributions.

A. G., B. J. J., and G.M. Q. contributed equally to this work. 


\section{APPENDIX A: TRANSCRIPT CONVENTIONS}

The transcripts use the following protocols, and are based on the work of [61] and [62].

:: $\quad$ Elongated words or vowels

Word Emphasized words are underlined

[ Start of overlapping speech of first speaker is shown with open bracket

/I Start of overlapping speech of second speaker

- $\quad$ Turns that are cut off by other speakers or end abruptly are marked with a hyphen

... Speaker turns that trail off are marked with an ellipsis

(()) Actions other than speech, including gestures and gaze, are represented in italics and surrounded by double parentheses

(\#)

(.)

$=$

(Speaker:) Quick verbal input of one speaker within a more

extended turn of another speaker

Pieces of speech that are difficult to discern are preceded or replaced

Length of a pause

Untimed pause

Latching between turns

\section{APPENDIX B: SECTION NO. 6 OF THE TRANSCRIPT}

No. 6: Discussion of conceptual ideas from post-it noting

Cade: Um, I have- I wrote this in the post as well, but um, to me the idea that- the eigenvalues of $L$ squared operator is hbar squared $L$ times $L$ plus one rather than little $L$ squared. Um, which at first seems really weird, but it makes a lot of sense when you think about it in terms of the uncertainty principle. So if you think about if it was just 1 squared and then you measured $1 z$ and found that 1 and $1 z$ have the same magnitude, then you would know the other components with certainty, thus violating the uncertainty principle, so to me that's kind of a- kind of a cool little illustration of the uncertainty principle that helped me.

46 Ayush: Mmm.

47 Brandon: It's interesting you say that heh. There was some materials designed in the past which tried to elicit some of that. Actually I think I the tutorial that we looked through, ERS was also trying to elicit some of that same reasoning, but currently, I think it was just a one question thing, and it might need more support.

\section{(Continued)}

48

Xavier: Like, the idea of it is kind of difficult for me right now, but I was thinking, uh, regarding the, like, observables, like you are again and again saying, like, they don't commute, so like exactly, is it like, all of them don't commute or is it like a portion of them doesn't commute and part of them commutes?

Cade: Like, so the components don't commute. So you can't know $1 x$ and $1 y$. So you- it's a vector right?

\section{Xavier: Yeah.}

51 Cade: You can't know the $x$ component and the $y$ component at the same time.

Xavier: So are there more components apart from $x$ and $y$ ? The way- Are we sure about that?

Cade: Are we sure about what?

54 Xavier: That apart from $x$ and $y$ component, is there any other component that we're aware of ().

55 Cade: Um, so we can know- so those are the only three components, right. It's a vector in three space. Um, but we can also measure the magnitude squared, and that turns out to commute with the components, $1 x, 1 y$, and $1 z$.

Xavier: Okay?

57 Cade: So we can know 1 squared and $1 x$, say, at the same time. But not $1 x$ and $1 y$

Xavier: Oh, then the questions doesn't make sense. (h) Ayush: That's okay.

Henry: I was thinking almost in like a way how- like asking the person how they would make a measurement of something, and then using that to think about the idea of what it means to measure something simultaneously versus in a sequence and whether it was would even be possible to measure two quantities at the same time. So, like, could they think of a way to measure the $1 x$ and the $1 y$ component at the same time if that makes sense.

Ayush: Mmm. I was going on something very very close to D- what you were saying Henry. I was thinking that it could be wonderful to think about, like, something that is focused on simultaneous versus repeated measurement. Sorry, not repeated but sequential, right. And I was playing around with some ideas of, like, whether we can think of creating coin systems because coins also have a heads or tails two state essentially. But then I can also create ensembles of coins, but I can also put, like, two coins in a box and do all of those kinds of things to try and think about what would it look like to- and then you can have some scrambling system where you can shake up the box. But either that or there was in Griffiths, there was a whole page where there's, like, a dialog around that same thing is that, "Can you measure $s x$ and $s z$ at the same time and what does that mean?" But basically it pivoted on the idea of simultaneous versus sequential measurement. And what does that mean. 
[1] J. L. Docktor and J. P. Mestre, Synthesis of disciplinebased education research in physics, Phys. Rev. ST Phys. Educ. Res. 10, 020119 (2014).

[2] D. E. Meltzer and R. K. Thornton, Resource letter ALIP-1: active-learning instruction in physics, Am. J. Phys. 80, 478 (2012).

[3] P. S. Shaffer and L. C. McDermott, Research as a guide for curriculum development: An example from introductory electricity. Part II: Design of instructional strategies, Am. J. Phys. 60, 1003 (1992).

[4] D. C. Meredith and E. F. Redish, Reinventing for lifesciences majors, Phys. Today 66, No. 7, 38 (2013).

[5] K. E. Matthews, Five propositions for genuine students as partners practice, Int. J. Students as Partners 1 (2017).

[6] E. Dunne, R. Zandstra, T. Brown, and T. Nurser, Students as change agents: New ways of engaging with learning and teaching in higher education (2011), https://dera.ioe.ac.uk/ $14767 /$.

[7] L. Mercer-Mapstone, S. L. Dvorakova, K. E. Matthews, S. Abbot, B. Cheng, P. Felten, and K. Swaim, A systematic literature review of students as partners in higher education, Int. J. Students as Partners 1 (2017).

[8] J. Bron and W. Veugelers, Why we need to involve our students in curriculum design: Five arguments for student voice, Curriculum Teaching Dialogue 16, 125 (2014).

[9] K. E. Matthews, A. Cook-Sather, A. Acai, S. L. Dvorakova, P. Felten, E. Marquis, and L. Mercer-Mapstone, Toward theories of partnership praxis: An analysis of interpretive framing in literature on students as partners in teaching and learning, Higher Educ. Res. Dev. 38, 280 (2019).

[10] G. M. Quan, J. C. Corbo, N. D. Finkelstein, A. Pawlak, K. Falkenberg, C. Geanious, and D. L. Reinholz, Designing for institutional transformation: Six principles for department-level interventions, Phys. Rev. Phys. Educ. Res. 15, 010141 (2019).

[11] C. Bovill and C. J. Bulley, A model of active student participation in curriculum design: exploring desirability and possibility, in Improving Student Learning (ISL) 18: Global Theories and Local Practices: Institutional, Disciplinary and Cultural Variations, edited by C. Rust, Improving Student Learning (Oxford Brookes University: Oxford Centre for Staff and Learning Development, Oxford, 2011), pp. 176-188.

[12] M. Healey, A. Flint, and K. Harrington, Engagement through Partnership: Students as Partners in Learning and Teaching in Higher Education (HEA, York, 2014).

[13] K. Tobin, Learning to teach through coteaching and cogenerative dialogue, Teaching Educ. 17, 133 (2006).

[14] J. C. Yip, K. Sobel, C. Pitt, K. J. Lee, S. Chen, K. Nasu, and L. R. Pina, Examining adult-child interactions in intergenerational participatory design, in Proceedings of the 2017 CHI Conference on Human Factors in Computing Systems (ACM, Denver CO, 2017), pp. 5742-5754.

[15] J. M. Carroll, Encountering others: Reciprocal openings in participatory design and user-centered design, HumanComputer Interactions 11, 285 (1996).

[16] A. Druin, Cooperative inquiry: developing new technologies for children with children, in Proceedings of the SIGCHI Conference on Human Factors in Computing Systems (ACM, Pittsburgh, PA, 1999), pp. 592-599.
[17] B. Kirshner and J. L. Polman, Adaptation by design: A context-sensitive, dialogic approach to interventions, Natl. Soc. Study Educ. Yearbook 112, 215 (2013).

[18] V. Svihla, Advances in design-based research, Frontline Learn. Res. 2, 35 (2014).

[19] M. Bang and S. Vossoughi, Participatory design research and educational justice: Studying learning and relations within social change making, Cognition and Instruction 34, 173 (2016).

[20] S. Vakil, M. McKinney de Royston, N. I. Suad Nasir, and B. Kirshner, Rethinking race and power in design-based research: Reflections from the field, Cognit. Instr. 34, 194 (2016).

[21] J. Roschelle, W. R. Penuel, and N. Schechtman, Co-design of innovations with teachers: Definition and dynamics, in Proceedings of the 7th International Conference on Learning Sciences (International Society of the Learning Sciences, Bloomington, IN, 2006), pp. 606-612.

[22] M. S. Sabella, A. G. Van Duzor, and F. Davenport, Leveraging the expertise of the urban STEM student in developing an effective LA Program: LA and Instructor Partnerships, in Proceedings of the 2016 Physics Education Research Conference, Sacramento, CA (AIP, New York, 2016), pp. 288-291.

[23] C. Bovill, A framework to explore roles within studentstaff partnerships in higher education: Which students are partners, when, and in what ways?, Int. J. Students as Partners 1 (2017).

[24] S. R. Arnstein, A ladder of citizen participation, J. Am. Inst. Planners 35, 216 (1969).

[25] A. S. Potvin, R. G. Kaplan, A. G. Boardman, and J. L. Polman, Configurations in Co-Design: Participant structures in partnership work, in In Connecting Research and Practice for Educational Improvement (Routledge, London, 2017), pp. 135-149.

[26] P. Felten, Emotion and partnerships, Int. J. Students as Partners 1 (2017).

[27] C. Bovill, K. Morss, and C. Bulley, Should students participate in curriculum design? Discussion arising from a first year curriculum design project and a literature review, Pedagogical Res. Maximising Educ. 3, 2 (2009).

[28] A. Cook-Sather, Authorizing students' perspectives: Toward trust, dialogue, and change in education, Educ. Res. 31, 3 (2002).

[29] H. B. Carlone and S. M. Webb, On (not) overcoming our history of hierarchy: Complexities of university/school collaboration, Sci. Educ. 90, 544 (2006).

[30] K. O'Connor, C. Hanny, and C. Lewis, Doing "business as usual": Dynamics of voice in community organizing talk, Anthrop. Educ. Q. 42, 154 (2011).

[31] C. E. Coburn, S. Bae, and E. O. Turner, Authority, status, and the dynamics of insider-outsider partnerships at the district level, Peabody J. Educ. 83, 364 (2008).

[32] S. J. Derry, R. D. Pea, B. Barron, R. A. Engle, F. Erickson, R. Goldman, and B. L. Sherin, Conducting video research in the learning sciences: Guidance on selection, analysis, technology, and ethics, J. Learn. Sci. 19, 3 (2010).

[33] B. Jordan and A. Henderson, Interaction analysis: Foundations and practice, J. Learn. Sci. 4, 39 (1995). 
[34] C. Goodwin, Participation, stance and affect in the organization of activities, Discourse Soc. 18, 53 (2007).

[35] J. P. Gee, An Introduction to Discourse Analysis: Theory and Method (Routledge, London, 2004).

[36] E. A. Schegloff, Sequence Organization in Interaction: A Primer in Conversation Analysis I (Cambridge University Press, Cambridge, England, 2007), Vol. 1.

[37] E. A. Schegloff, G. Jefferson, and H. Sacks, The preference for self-correction in the organization of repair in conversation, Language 53, 361 (1977).

[38] R. S. Siegler and K. Crowley, The microgenetic method: A direct means for studying cognitive development, Am. Psychol. 46, 606 (1991).

[39] O. Parnafes and A. A. diSessa, Microgenetic learning analysis, Hum. Dev. 56, 5 (2013).

[40] H. Sacks, E. A. Schegloff, and G. Jefferson, A simplest systematics for the organization of turn taking for conversation, in Studies in the Organization of Conversational Interaction (Academic Press, New York, 1978), pp. 7-55.

[41] E. A. Schegloff, Overlapping talk and the organization of turn-taking for conversation, Language Soc. 29, 1 (2000).

[42] C. Goodwin and M.H. Goodwin, Participation. A companion to linguistic anthropology, 222244 (2004).

[43] M. H. Goodwin, Participation, affect, and trajectory in family directive/response sequences, Text Talk 26, 515 (2006).

[44] J. P. Gee, Chapter 3: Identity as an analytic lens for research in education, Rev. Res. Educ. 25, 99 (2000).

[45] L. D. Conlin and R. E. Scherr, Making space to sensemake: epistemic distancing in small group physics discussions, Cognit. Instr. 36, 396 (2018).

[46] A. B. Tsui, Beyond the adjacency pair, Lang. Soc. 18, 545 (1989).

[47] H. Mehan, 'What time is it, Denise?': Asking known information questions in classroom discourse, Theory Into Practice 18, 285 (1979).

[48] G. B. Bolden, Implementing incipient actions: The discourse marker 'so'in English conversation. J. Pragmatics 41, 974 (2009).

[49] F. Davenport, F. Amezcua, M. Sabella, and A. Van Duzor, Exploring the underlying factors in learning assistantfaculty partnerships, in Proceedings of the 2017 Physics Education Research Conference, Cincinnati, OH (AIP, New York, 2017).

[50] T. M. Philip and A. Gupta, Emerging perspectives on the co-construction of power and learning in the learning sciences, mathematics education, and science education, Rev. Res. Educ. 44, 195 (2020).

[51] R. A. Hart, Children's participation: From tokenism to citizenship, Innocenti Essays No. 4 (1992), https://www .unicef-irc.org/publications/100-childrens-participationfrom-tokenism-to-citizenship.html.

[52] A. Cook-Sather, C. Bovill, and P. Felten, Engaging Students as Partners in Learning and Teaching: A Guide for Faculty (John Wiley \& Sons, New York, 2014).

[53] A. Cook-Sather and P. Felten, Where student engagement meets faculty development: How student-faculty pedagogical partnership fosters a sense of belonging, Student Engagement Higher Educ. J. 1, 3 (2017).

[54] T. Hermsen, T. Kuiper, F. Roelofs, and J. van Wijchen, Without Emotions, Never a Partnership!, Int. J. Students as Partners 1 (2017).

[55] A. Cook-Sather, Resisting the impositional potential of student voice work: Lessons for liberatory educational research from poststructuralist feminist critiques of critical pedagogy, Discourse: Studies Cultural Politics Educ. 28, 389 (2007).

[56] M. Scardamalia and C. Bereiter, Higher levels of agency for children in knowledge building: A challenge for the design of new knowledge media, J. Learn. Sci. 1, 37 (1991).

[57] M. Scardamalia, Collective Cognitive Responsibility for the Advancement of Knowledge, in Liberal Education in a Knowledge Society, edited by B. Smith (Open Court, Chicago, IL, 2002), pp. 67-98.

[58] C. I. Damşa, P. A. Kirschner, J. E. Andriessen, G. Erkens, and P. H. Sins, Shared epistemic agency: An empirical study of an emergent construct, J. Learn. Sci. 19, 143 (2010).

[59] D. R. Dounas-Frazer, J. T. Stanley, and H. J. Lewandowski, Student ownership of projects in an upper-division optics laboratory course: A multiple case study of successful experiences, Phys. Rev. Phys. Educ. Res. 13, 020136 (2017).

[60] A. J. Rodriguez, Managing institutional and sociocultural challenges through sociotransformative constructivism: A longitudinal case study of a high school science teacher, J. Res. Sci. Teach. 52, 448 (2015).

[61] E. Schegloff, G. Jefferson, and H. Sacks, A simplest systematics for the organization of turn-taking for conversation, Language 50, 696 (1974).

[62] G. Jefferson, Glossary of transcript symbols with an introduction. G. H. Lerner (Yay. haz.), Conversation Analysis: Studies from the First Generation içinde (2004) (s. 13-23). 